\title{
Ancient Observation of Spinal Cord Injury: The Case of the Assyrian Lion
}

\author{
Gustavo J. Luvizutto ${ }^{1}$, Emerson G.M. Siqueira ${ }^{2}$, Pedro Tadao Hamamoto Filho ${ }^{2}$, Viviane H.F. Zétola ${ }^{3}$, Marcos C. Lange ${ }^{3}$, \\ Hélio A.G. Teive ${ }^{3}$, Luiz A.L. Resende ${ }^{2}$, Rodrigo Bazan ${ }^{2}$
}

\author{
Key words \\ - Dermatomes \\ - History of neurology \\ - Paraplegia \\ - Spinal cord injury
}

From the ${ }^{\mathbf{1}}$ Univ. Federal do Triângulo Mineiro, Uberaba;

${ }^{2}$ Department of Neurology, Psychology, and Psychiatry, Univ. Estadual Paulista/Botucatu Medical School, Botucatu; and

${ }^{3}$ Univ. Federal do Paraná, Curitiba, Brazil

To whom correspondence should be addressed:

Pedro Tadao Hamamoto Filho, M.D., M.Sc.

[E-mail:phamamoto@fmb.unesp.br]

Citation: World Neurosurg. (2018) 116:149-151.

https://doi.org/10.1016/j. wneu.2018.05.083

Journal homepage: www.WORLDNEUROSURGERY.org

Available online: www.sciencedirect.com

1878-8750/\$ - see front matter (C) 2018 Elsevier Inc. All rights reserved.

\section{INTRODUCTION}

Paraplegia is paralysis of the legs or the lower parts of the body. The International Standards for Neurological Classification of Spinal Cord Injury updated this definition to include the impairment or loss of motor or sensory function in the thoracic, lumbar, or sacral segments of the spinal cord secondary to damaged neural elements within the spinal canal. ${ }^{\mathrm{I}, 2}$ The description of paraplegia is considered a milestone in the history of neurology; here, we present I of the oldest observations of spinal cord injury, which was made by the Assyrian people.

\section{THE ASSYRIAN PARAPLEGIC LION}

In ancient Assyria, lion hunting was a ritualized activity reserved for kings. These hunts were symbolic of the ruling monarch's duty to protect and fight for his people. The Assyrian kings hunted lions for political and religious purposes and to demonstrate their power. To encourage the lion out of his cage and onto the Assyrian plains, a servant would raise the cage door and start running. The lion was beaten by dogs and beaters, forcing the lion to go to the king. The king would kill the lion from a chariot with his bow and

The description of paraplegia is considered a milestone in the history of neurology. The Egyptians provided excellent descriptions of spinal cord injuries, the Bible has several references to paraplegia, and, more recently, the pioneers of neurology described the classic syndromes related to spinal injuries and paraplegia. Here, we describe an ancient observation by the Assyrian people of paraplegia in an animal. In ancient Assyria, lion hunting was a ritualized activity conducted for political and religious purposes. The Lion Hunt of Ashurbanipal, a series of Assyrian palace reliefs from the North Palace at Nineveh dating from approximately 645 BCE, which is now in the British Museum in London, UK, shows King Ashurbanipal hunting lions. Applying modern knowledge of mammalian dermatomes to the images, we reveal a detailed and precise observation of paraplegia after spinal cord injury.

arrow or spear. Sometimes, the king would kill it on foot with a sword. He would do this by holding the lion by the mane and then thrusting the sword into the lion's throat. Then, when the lion was dead, the king would pour a liquid over it and give a speech to the city's god thanking him, so the lion's evil spirit would not come back and haunt him. Expert spearmen and archers would protect the king. Sometimes the king would invite nobles to accompany him. ${ }^{3}$

The Lion Hunt of Ashurbanipal, a series of Assyrian palace reliefs from the North Palace at Nineveh dating from approximately $645 \mathrm{BCE}$, which is now in the British Museum in London, UK, shows King Ashurbanipal hunting lions (Figure 1). In fact, the royal lion hunt was the staged and ritualized killing by the king of lions that had been captured and released into an arena. The realism of the lions in the reliefs has always been praised, although the pathos modern viewers tend to feel was perhaps not part of the Assyrian response.

Applying modern knowledge of mammalian dermatomes ${ }^{4,5}$ to the images (Figure 2), we can describe the 3 arrows in the following manner:

\section{Arrow 1}

The arrow did not cross the spine and was inserted into the muscular region of the animal's back. There was no neurologic involvement, because the forelimbs supported the animal's weight on the ground; there was good tropism and muscular strength. This region of cervicothoracic intumescence is seen in both domestic and wild animals of the family Felidae. Lesions in this region may generate signs of inferior motor neuron dysfunction in the thorax, with normal or spastic hindlimbs.

\section{Arrow 2}

The arrow traversed the spine, with probable involvement of the spinal cord in the lumbar segment, identified by the loss of support by the hindlimbs. This involvement can be observed by the possible decrease in muscle tone when forelimbs and hindlimbs are compared, with the hindlimbs oriented in the caudal direction. The most likely lesion is in the lumbar region, with involvement of the lumbar medullar portion of the spinal cord. Therefore, the resulting posture is what would be expected according to the analysis of the insertion site of the arrow and the apparent loss of muscle tone. In this type of injury, we may have a victim with sphincter hypotonia, and also muscle hypotonia, including the bladder detrusor. In addition, hyporeflexia would be expected in the hindlimbs, particularly in the patellar reflex. 


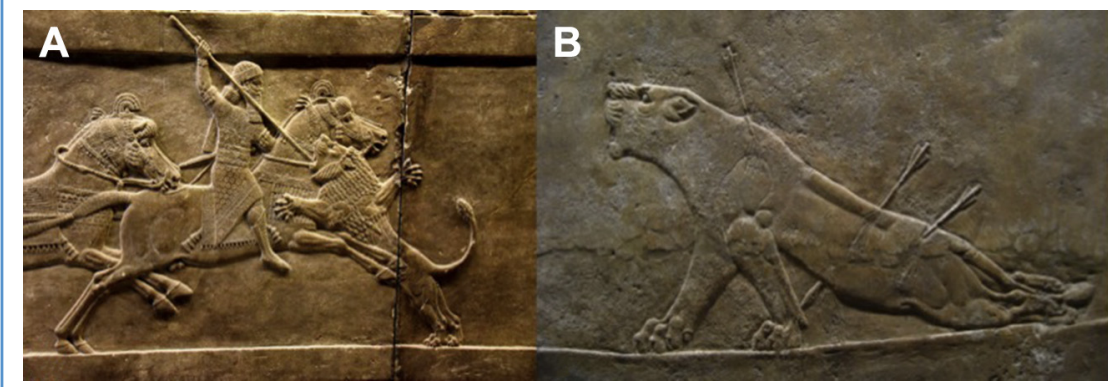

Figure 1. (A) Sculpted reliefs depicting Ashurbanipal, the last great Assyrian king, hunting lions Gypsum Hall relief from the North Palace of Nineveh (Iraq), c. 645-635 BCE, British Museum. (B) The image of the hunted lion, showing 3 arrows in his back; the arrow traversing the spine in the lower back probably injured the spinal cord.

\section{Arrow 3}

The arrow traversed the spine, with probable involvement of the spinal cord in the sacral segment. There was neurologic involvement, but there was an overlap with the arrow that affected the lumbar region.

\section{DISCUSSION}

Paraplegia is a well-established condition that occurs with complete or incomplete spinal cord lesions. Thorough descriptions of spinal cord lesions have made it possible to understand the history of neurologic knowledge.
The first clinical report of spinal cord lesions was registered in the Edwin Smith papyrus. In 1930, the Egyptologist James Henry Breasted translated a papyrus, the original content of which was probably written during the seventeenth century BCE. This papyrus contains the descriptions of 48 traumatic cases, 6 involving the cervical spine, with 2 of those 6 clearly describing injuries to the spinal cord. The anatomy of the lesions is described, as are strategies for how to manage each case. Some have suggested that the author of the papyrus was Imhotep, but the original authorship is controversial. ${ }^{6-8}$ Later, King

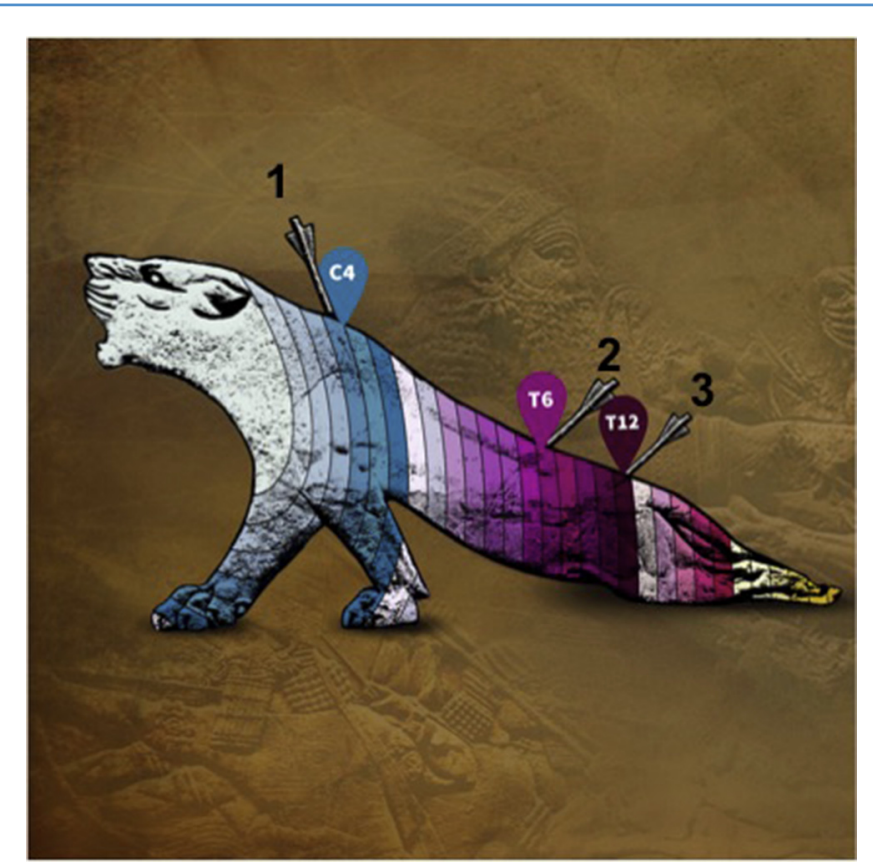

Figure 2. The hunted lion image overlapped by a schematic of the dermatomes in mammals. Arrows 1, 2, and 3 are identified as described in the text.
Seti I (I290-I279 BCE) built the Temple of Amun in Karnak, and on the north wall of the Hypostyle Hall there are the Battle Reliefs, which present graphic representations of neurologic injuries, including spine lesions, observed in battles. ${ }^{9}$

The Old Testament of the Bible also has several references to paraplegia, such as the mention of Mephibosheth (IOoo BCE), grandson of King Saul. ${ }^{\text {IO }}$

In the fourth century BCE, Hippocrates, a leading figure in the history of medicine, also provided detailed descriptions of spine lesions, such as tuberculous spondylitis and traumatic injuries. Additionally, he created some principles for spine management that were observed for centuries, including the concept that some maneuvers could worsen the prognosis. ${ }^{\mathrm{II}-\mathrm{I} 3}$

Galen (I29-200 AD) was the first to perform several anatomic experiments, including early studies on the effects of transection of the spinal cord. Combining the medical heritage of the Hippocratic, Alexandrian, and ancient medical schools in his studies, he was able to describe the specific loss of function below the level of transection. ${ }^{\text {I4, I5 }}$

Other authors provided significant advances in the understanding of the anatomy and physiology of the spine. Leonardo da Vinci (I452-I5I9) made the first attempts to describe spinal stability, Andreas Vesalius (15I4-I564) made a very precise description of spinal anatomy, and Giovanni Alfonso Borelli (1608-1679) introduced the concept of spinal biomechanics. ${ }^{\mathrm{I}}$ Gerard Blaes (Blasius) (16271682) described the anterior and posterior spinal roots and also the white matter surrounding the $\mathrm{H}$-shaped formation of the gray matter. ${ }^{17}$ Domenico Cotugno (1736-I8) described cerebrospinal fluid and formulated the hypothesis of nerve sheath involvement in the origin of sciatica. ${ }^{\text {I8, I9 }}$ In 1746 , William Hunter founded a medical school, the Great Windmill Street School of Anatomy, where several outstanding physicians, such as Percival Pott (1714I788), Astley Cooper (I768-I84I), John Abernethy (1764-I83I), and Everard Home (I756-I832) studied spinal disorders. ${ }^{20}$ In I849, Charles-Edouard Brown-Séquard (I8I7-I894) published the first description of medullary syndrome, a lateral hemisection causing 
ipsilateral hyperesthesia and lost or diminished sensation in the contralateral limb. ${ }^{2 \mathrm{I}-23}$ Wilhelm Heinrich Erb (I840I92I) made early observations of tabes dorsalis, also known as syphilitic myelopathy, which was associated with a major epidemic of infectious diseases in Europe. $^{24}$ William Gowers (I845-I9I5) was the first to identify a removable spinal tumor, and he was an enthusiastic supporter of the importance of clinical examination for neurologic diagnoses. ${ }^{25}$ This spinal tumor was successfully removed by Victor Horsley (I857-I9I6), who also made important contributions to the surgical management of spinal lesions. ${ }^{26}$ These observations and studies contributed to the understanding of spinal cord lesions, and they are part of the history of neurology and neurosurgery.

Currently, several conditions are recognized as causes of paraplegia, such as trauma, infections, autoimmune diseases, tumors, and circulatory abnormalities. Individuals with severe fracture dislocations may be neurologically intact, whereas some present with symptomatic spinal cord injury without any radiologic abnormalities. ${ }^{27-29}$

Notwithstanding the cause of the spine lesion, humans are highly dependent on descending pathways to maintain control of locomotion, and the neural networks below the level of the lesion are not as easily activated as they are in animals. ${ }^{30}$ Experimental studies on locomotor activity and its relation to spine injuries were performed in felines mainly during the twentieth century. These experiments showed that cats can recover spontaneous hindlimb locomotion on a treadmill after a complete spinal cord transection, but they cannot recover voluntary locomotion. ${ }^{3 \mathrm{I}}$ The representation of the Assyrian lion is very similar to the patterns observed in cats with spine injuries, namely, the inability to support the posterior back weight, lack of voluntary control of the hindlimbs, absence of sustained coordination between the forelimbs and hindlimbs during quadrupedal locomotion, and loss of balance control. ${ }^{32}$

In this historical vignette, we show a precise, accurate, and detailed ancient observation of paraplegia in an animal. This depiction may have been an involuntary contribution of the Assyrian people to the knowledge of comparative anatomy and neurology.

\section{ACKNOWLEDGMENT}

We thank the British museum in London for the authorization to use the images and we thank Mr. Cristiano de Almeida Akama for his support on the illustration of the lion's dermatomes.

\section{REFERENCES}

I. Haerer A, DeJong RN. Disorders of the spinal cord. In: DeJong RN, ed. DeJong's The Neurologic Examination. Philadelphia: Lippincott; I992:585-586.

2. Haerer A, DeJong RN. Motor strength and power. In: DeJong RN, ed. DeJong's The Neurologic Examination. Philadelphia: Lippincott; I992:335-339.

3. Radner K. Ancient Assyria: A Very Short Introduction. Oxford: Oxford University Press; 2015.

4. Hekmatpanah J. Organization of tactile dermatomes, CI through L4, in cat. J Neurophysiol. Ig6r; 24:I29-I4O.

5. Reid KH. Dermatomes and skin innervation density in the cat's tail. Exp Neurol. I970;26:I-I6.

6. Van Middendorp JJ, Sanchez GM, Burridge AL. The Edwin Smith papyrus: a clinical reappraisal of the oldest known document on spinal injuries. Eur Spine J. 2010;I9:I8I5-I823.

7. Breasted JH. Edwin Smith Surgical Papyrus. Chicago: University of Chicago Press; I930.

8. Hughes JT. The Edwin Smith Surgical Papyrus: an analysis of the first case reports of spinal cord injuries. Paraplegia. I988;26:71-82.

9. Sanchez GM. A neurosurgeon's view of the battle reliefs of King Sety I: aspects of neurological importance. J Am Res Cent Egypt. 2000;37:I43-I65.

Io. Bedbrook GM, Sedgley GI. The management of spinal injuries-past and present. Int Rehab Med. I980;2:45-6I.

II. Marketos SG, Skiadas P. Hippocrates. The father of spine surgery. Spine. I999;24:I38I-I387.

I2. Korres DS, Mavrogenis AF, Papagelopoulos PJ. Hippocratic beliefs on spine and spinal cord injuries: new or old notions? Orthopedics. 2004;27:1078-1079.

13. Korres D, Markatos K, Chytas D, Andreakos A, Mavrogenis A. Injuries of the spine and of the spinal cord in the hippocratic corpus of medicine. Int Orthop. 2017;4I:2627-2629.

I4. De G usu partium. Galen on the Usefulness of the Parts of the Body (Peri Chreias Morion). Ithaca, NY: Cornell University Press; Ig68.

15. Marketos SG, Skiadas PK. Galen: a pioneer of spine research. Spine. 1999;24:2358-2362.

I6. Sanan A, Rengachary SS. The history of spinal biomechanics. Neurosurgery. I996;39:657-668.

I7. Markatos K, Laios K, Korres D, Tzivra A, Tsoutsos S, Androutsos G. Gerard Blaes (Blasius) (I627-I682): the Dutch physician and chemist, his work and description of the spinal cord. World Neurosurg. 2017;IO4:I48-I5I.
I8. Manni E, Petrosini L. Domenico Cotugno, a pioneer in neurosciences. J Hist Neurosci. I997; 6:I24-I32.

I9. Pearce JMS. Cotugno and cerebrospinal fluid J Neurol Neurosurg Psychiatry. 2004;75:I299.

20. Weiner MF, Silver JR. The contribution to our understanding of spinal disorders by the great Windmill Street School of Anatomy. Spinal Cord. 20II;49:323-332.

2I. Brown-Sequard E. De la transmission croisée des impressions sensitives par la moelle epinière. C R Soc Biol (Paris, France). I850;2:33.

22. Charcot JM. Du tabes dorsal spasmodique. Prog Med (Paris). I876;45:737-738.

23. Tattersall R, Turner B. Brown-Séquard and his syndrome. Lancet. 2000;356:6I-63.

24. Mahmoudi Nezhad GS, Dalfardi B, Ghanizadeh A Wilhelm Heinrich Erb (I840-I92I). J Neurol. 20I4 26I:I846-I847.

25. Mulholland RC. Sir William Gowers I845-I9I5 Spine. I996;21:IIO6-IIIo.

26. Tan TC, Black PM. Sir Victor Horsley (I857-Igr6): pioneer of neurological surgery. Neurosurgery. 2002;50:607-6II

27. Zhang S, Yan TB. Severe fracture-dislocation of the thoracic spine without any neurological deficit. World J Surg Oncol. 20I7;15:3.

28. Salkov M, Tsymbaliuk V, Dzyak L, Rodinsky A, Cherednichenko Y, Titov G. New concept of pathogenesis of impaired circulation in traumatic cervical spinal cord injury and its impact on disease severity: case series of four patients. Eur Spine J. 20I6;25:II-I8.

29. Pang D, Pollack IF. Spinal cord injury without radiographic abnormality in children: the SCIWORA syndrome. J Trauma. I989;29:654-664.

30. Yang JF, Gorassini M. Spinal and brain control of human walking: implications for retraining of walking. Neuroscientist. 2006;12:379-389.

3I. Rossignol S, Bouyer L. Adaptive mechanisms of spinal locomotion in cats. Integr Comp Biol. 2004;44:71-79.

32. Majczyński H, Sławińska U. Locomotor recovery after thoracic spinal cord lesions in cats, rats and humans. Acta Neurobiol Exp (Wars). 2007;67:235-257.

Conflict of interest statement: The authors declare that the article content was composed in the absence of any commercial or financial relationships that could be construed as a potential conflict of interest.

Received 22 February 2018; accepted 12 May 2018

Citation: World Neurosurg. (2018) 116:149-151 https://doi.org/10.1016/j.wneu.2018.05.083

Journal homepage: www.WORLDNEUROSURGERY.org Available online: www.sciencedirect.com 1878-8750/\$ - see front matter (C) 2018 Elsevier Inc. All rights reserved. 